\title{
Polar Research and the Secrets of the Arctic
}

\author{
Torbjørn Pedersen \\ Faculty of Social Sciences, Nord University
}

\begin{abstract}
The advantages that some military establishments have enjoyed in the remote Arctic region are diminishing. The military secrets of the Arctic Ocean are being progressively uncloaked, as civilian polar research expands into areas previously known only to a few. This study examines the security ramifications of broadened international research into what has been the most inhospitable and exclusive operational area on Earth. Firstly, the study argues that successful military operations in the Arctic depend on extended knowledge about area-specific issues related to e.g. the upper atmosphere and magnetosphere, weather, sea ice, ocean structure and dynamics, seafloor bathymetry and sediments, as well as reliable target detection systems. Secondly, it finds that a number of nations, both Arctic and non-Arctic, have stepped up their polar research in recent years. Secrets once held by a few are now accessible to many through international cooperation, data-sharing and open-access publishing. Finally, the study concludes that knowledge proliferation is likely to level the Arctic battlefield. Lending terms from Mica Endsley's three-level Situation Awareness model, polar research will result in increasingly shared perceptions about the Arctic operational environment, contribute to a more uniform comprehension of the elements, and even enable new actors to project a future state of the Arctic environment.
\end{abstract}

Keywords: Arctic; dual-use; polar research; Situation Awareness; Tactical Advantage; undersea warfare

Responsible Editor: Øyvind Ravna, UiT - The Arctic University of Norway, Tromsø, Norway

Received: September 2018; Accepted: December 2018; Published: January 2019

\footnotetext{
^Correspondence to: Torbjørn Pedersen, email: torbjorn.pedersen@gmail.com

(C) 2019 Torbjørn Pedersen. This is an Open Access article distributed under the terms of the Creative Commons Attribution-NonCommercial 4.0 International License (https://creativecommons.org/licenses/by-nc/4.0/), allowing third parties to share their work (copy, distribute, transmit) and to adapt it, under the condition that the authors are given credit, that the work is not used for commercial purposes, and that in the event of reuse or distribution, the terms of this license are made clear.

Citation:Torbjørn Pedersen. "Polar Research and the Secrets of the Arctic"Arctic Review on Law and Politics, Vol. 10, 2019, pp. 103-129. http://dx.doi.org/10.23865/arctic.v10.1501
} 


\section{Introduction}

Know Heaven,

Know Earth, And your victory

Is Complete

Sun-Tzu, 544-496 BC ${ }^{1}$

\subsection{Introduction}

International polar researchers are relentlessly uncloaking the secrets of the Arctic seas, including their detailed seafloor bathymetry, ocean currents and shifting temperature and salinity layers, as well as real-time variations in the atmospheric weather and the ionosphere above. As data and knowledge about the natural environment of the high latitudes is accumulated and shared internationally - through e.g. international workshops, publications, and data-sharing - nations will increasingly acquire a shared basis for understanding the region's operational environment.

The purpose of this study is to examine how extensive polar research in the Arctic, as well as international research collaboration, affects the traditional advantages and disadvantages of the military actors in the region. The concepts of Situation Awareness $^{2}$ and Tactical Advantage will be brought into the discussion. Mica Endsley defines Situation Awareness as "the perception of the elements in the environment within a volume of time and space, the comprehension of their meaning, and the projection of their status in the near future" (italics added). ${ }^{3}$ Tactical Advantage is a zero-sum concept involving two players or more in a given encounter, where the tactical gains of one player correspond to tactical losses on the part of the other(s).

The study presents two sets of results. The first set lists environmental parameters that are fundamental to military operations in the Arctic. The second set is a brief overview of civilian polar research in the region that provides a vital understanding of these elements. In its concluding discussion, the study finds that knowledge about the Arctic environment is now comprehensive and has proliferated internationally. Ultimately, as nations gain a shared basis for understanding the unique elements of the Arctic environment and develop similar abilities to predict its future state - to achieve Situation Awareness - regional knowledge ceases to be a distinct Tactical Advantage. The Arctic battlefield will progressively become more levelled.

While civilian polar research certainly has military implications and may de facto serve dual purposes, the study does not presuppose or imply that the purposes of international polar research are other than peaceful. That would suggest a violation

1 Sun-Tzu, The Art of War (Penguin Books 2014), 81.

2 Situation Awareness and Situational Awareness are often used interchangeably in literature.

3 Mica Endsley, "Toward a Theory of Situation Awareness in Dynamic Systems". Human Factors fournal 37 (1995), 26. 
of international law. Marine research within other nations' areas of jurisdiction is regulated by the U.N. Convention on the Law of the Sea, part XIII. According to Article 240 (a), marine scientific research "shall be conducted exclusively for peaceful purposes". Furthermore, the 1920 Treaty Concerning Spitsbergen prohibits any use of the Svalbard islands for "warlike purposes". ${ }^{4}$ The effect outlined in this study's conclusions - a more levelled battlefield - is likely to take place regardless of the underlying motives of the polar research.

Nevertheless, military and civilian research are intertwined. Armed forces rely heavily on civilian research. Decades of massive Soviet research on meteorology, oceanography, ice and more has been acknowledged as one of the biggest assets of the Russian Northern Fleet. ${ }^{5}$ The U.S. Navy is regarded as the world's largest single funder of meteorological and oceanographic research, ${ }^{6}$ which provides for better physical battlespace awareness in their operational forces. ${ }^{7}$ Moreover, China's People's Liberation Army (PLA) is known to have strongly influenced the polar research programs of the Chinese Arctic and Antarctic Administration (CAA), the Polar Research Institute of China (PRIC) and China's State Oceanic Administration (SOA). ${ }^{8}$

The empirical basis of this study focuses on, though not exclusively, the European Arctic, given its crucial role in Russia's bastion defense as well as the region's strategic significance to all nations that rely on access to it or relate to Russia's strategic capabilities. The European Arctic also comprises the bulk of contributions to polar research. ${ }^{9}$

A significant share of international research in the Arctic has been conducted in Norwegian areas of jurisdiction, ${ }^{10}$ including Svalbard and its surrounding areas. This is also reflected in the results. This region is by far the most accessible part of the High Arctic, due to warm currents that keep waters relatively ice-free. In addition,

4 Article 9.

5 Andrei Kokoshin, cited in Kristian Åtland, "The Introduction, Adoption and Implementation of Russia's 'Northern Strategic Bastion' Concept, 1992-1999”. The Fournal of Slavic Military Studies 20 (2007), 499-528.

6 National Research Council (NRC), Environmental Information for Naval Warfare (The National Academies 2003).

7 William Burnett et al., "Overview of Operational Ocean Forecasting in the US Navy Past, Present, and Future". Oceanography 7 (2014), 24-31.

8 Bergin et al., "Cold Calculations: Australia's Antarctic Challenges". Strategic Insights 66 (2013); Anne-Marie Brady, China as a Polar Great Power (Cambridge University Press 2017); ---, "China's Expanding Interests in Antarctica”. Special Report. Australian Strategic Policy Institute, 2017; Linda Jacobsen \& Peng Jingchao, "China's Arctic Aspirations”. SIPRI Policy Paper 34 (November 2012).

9 Norwegian Joint Headquarters (NJHQ), Arsrapport 2017; Personal communication, 11 April and 10 October 2018.

10 NJHQ, Årsrapport 2017. 
Svalbard Airport Longyearbyen, at 78 degrees north, is the world's northernmost destination for regular airliner traffic. ${ }^{11}$

\subsection{The strategic Arctic - a short history}

Wedged between North America and Russia, the strategic significance of the Arctic has long been irreducible. ${ }^{12}$ From the introduction of the atomic bomb and the outbreak of the Cold War, the Soviet Union (and later Russia) and the United States have faced a mutual existential threat from across the polar region. With the development of missiles and long-range bombers in the 1950s, the region also offered the most expedient routes to possible targets on the other side. ${ }^{13}$

Advances in submarine technology had profound effects on Arctic geopolitics. With the introduction of a nuclear power source, submarines were enabled to operate submerged for weeks and months rather than days. Their survivability was vastly improved, making them a feared and effective "second-strike" deterrent against any pre-emptive nuclear first strike.

Submarine-launched ballistic missiles, introduced a few years later, enabled the submarines of the Soviet Northern Fleet to target North America without having to transit western anti-submarine warfare barriers outside Norway and in the GreenlandIceland-United Kingdom (GIUK) gap. ${ }^{14}$ For the first time, the largest of the Soviet fleets posed a threat from positions close to its heavily defended northern bastion. ${ }^{15}$

The Soviet Union's emerging bastion defense stirred considerable fears in Washington. In 1981, the United States and NATO countered with a new Concept of Maritime Operations, which underlined the need for forward operations, defense in depth and seizing the initiative at sea. The Supreme Allied Commander Atlantic, Harry D. Train II, explained that the new concept involved "sealing off the Soviet Navy in their home waters", ${ }^{16}$ while U.S. Secretary of the Navy, John F. Lehman, claimed that the United States would attack Soviet submarines "in the first five minutes of the war". ${ }^{17}$ Toward the end of the Cold War, the European Arctic had transformed into one of the most heavily militarized regions on Earth. ${ }^{18}$

11 Torbjørn Pedersen, “The Politics of Presence: Longyearbyen Dilemma”. Arctic Review on Law and Politics 8 (2017), 95-108.

12 Oran Young, Arctic Politics: Conflict and Cooperation in the Circumpolar North (University Press of New England, 1992).

13 Quoted in Kjetil Skogrand and RolfTamnes, Fryktens likevekt. Atombomben, Norge og verden (Oslo: Tiden Norsk forlag 2001), 62.

14 Norman Polmar \& Edward Whitman, "Hunters and Killers, Vol. II: Anti-Submarine Warfare from 1943". (Annapolis: Naval Institute Press, 2016).

15 Sergei Gorshkov, The Sea Power of the State (Oxford: Pergamon Press, 1979).

16 Quoted in Rolf Tamnes, The United States and the Cold War in the High North (Dartmouth Publishing, 1991), 283.

17 Quoted in Polmar and Whitman, "Hunters and Killers", 157.

18 Åtland, "The Introduction, Adoption and Implementation". 
While bringing about an East-West thaw and a sharp decline in naval activity, the break-up of the Soviet Union also reaffirmed the strategic role of the Arctic. The navy lost Baltic and Black Sea bases to Soviet successor states and had to rely even more heavily on its Arctic outlets to the North Atlantic.

The massive defense around Russia's strategic submarines and their bases still accounts for the geopolitical importance of the Arctic. ${ }^{19}$ The bastion defense includes conventional forces, a robust air defense of air force bases, anti-aircraft systems and early-warning radars across the Russian Arctic. ${ }^{20}$ For additional depth, Russia is likely to deploy considerable anti-access/area denial (A2/AD) capabilities inside the Greenland-Iceland-United Kingdom (GIUK) gap during conflict. ${ }^{21}$

Since the 2000s, the Arctic has also gained strategic significance in new but equally pronounced ways. In 2008, Russia named the Arctic its "primary resource base" for the $21^{\text {st }}$ century. ${ }^{22}$ The region, which is a treasury of oil, gas and mineral deposits, already accounts for approximately 20 percent of Russia's Gross Domestic Product (GDP) and is likely to become even more significant to Russian economic development in the future. ${ }^{23}$

Non-Arctic nations are also showing more interest in the region, as it becomes more accessible amid climate change. ${ }^{24}$ Notably, China has come to define itself as a coming polar great power ${ }^{25}$ and has demonstrated a keen interest in the region's resource potential as well as in new sea lines of communication (SLOCs) - a "Polar Silk Road" - across the Arctic Ocean. ${ }^{26}$ In its 2018 Arctic Policy, the government asserted that the Arctic region has "a vital bearing on the interests of States outside the region and the interests of the international community as a whole, as well as on the survival, the development, and the shared future of mankind". ${ }^{27}$

\subsection{Theoretical concepts}

This study draws on theoretical concepts related to military operations, most notably Situation Awareness and Tactical Advantage. Situation Awareness, sometimes labelled battlespace awareness, often refers to "the perception of the elements in the

19 Ekspertgruppen for forsvaret av Norge, Et felles løft (Oslo: Forsvarsdepartementet 2015).

20 Ibid.

21 Ian Williams, “The Russia - NATO A2AD Environment”. Missile Threat, CSIS, 3 January 2017.

22 Kristian Åtland, "Russia's Armed Forces and the Arctic: All Quiet on the Northern Front?". Contemporary Security Policy 32 (2011), 267-285.

23 Lincoln Edson Flake, "Russia's Security Intentions in a Melting Arctic". Military and Strategic Affairs 6 (2008), 99-116.

24 Scott Borgerson, "Arctic Meltdown: The Economic and Security Implications of Global Warming”. Foreign Affairs 87 (2008), 63-77.

25 Brady, China as a Polar Great Power.

26 China State Council, “China’s Arctic Policy”, 26 January 2018.

27 Ibid. 


\section{Torbjørn Pedersen}

environment within a volume of time and space, the comprehension of their meaning, and the projection of their status in the near future" ${ }^{28}$ This definition, developed by Mica Endsley, suggests three levels of Situation Awareness, and the terminology is widely embraced by western military establishments. ${ }^{29}$ The definition also echoes the three-level distinction made by intelligence communities between data, information and intelligence, in which the latter usually has a predictive element.

While Endsley has increasingly taken a user-centered approach to Situation Awareness, ${ }^{30}$ that is, the individual's cognitive ability to make decisions in a highly dynamic environment, the concept is also widely applied at the team or shared level. ${ }^{31}$ In general, the team or shared models see the collective Situation Awareness (SA) as the aggregate of individual SA, the SA of other team members, the SA of the entire team, and/or the common, or shared, picture. ${ }^{32}$

This study adapts and adopts the Situation Awareness concept to address the ability of a given nation's armed forces to operate effectively in, and take advantage of, the Arctic operational environment. Inevitably, using the concept this way will highlight systems over "the human factor" and thus depart from Endsley's individual and cognitive emphasis. The study borrows the three-level perception-comprehensionprojection terminology, but only to indicate different levels of understandings and abilities. A higher level of Situation Awareness here suggests an enhanced ability to operate within a given environment and predict the future state of its elements.

Tactical Advantage is a zero-sum concept that involves at least two players. The tactical advantage of A over B is, put bluntly, an advantage that helps A defeat B in a battle. Hence, a tactical gain to A is a tactical loss to B. "In combat an environmental advantage for one side always means some degree of misfortune for the other," notes Harold Winters. ${ }^{33}$ The zero-sum concept is also imbedded in the security dilemma, ${ }^{34}$ which postulates that the more secure one player is, through the acquisition of more military power, the less secure the other player(s). The concept is widely applied in arms race explanations and systemic theories of international politics, specifically those highlighting relative power relationships among the great powers in the

28 Endsley, "Toward a Theory", 26.

29 See e.g., NATO, Comprehensive Operations Planning Directive (2013); Forsvaret, Forsvarets fellesoperative doktrine (2007 and 2014).

30 Also see Mica Endsley \& Debra G. Jones, Designing for Situation Awareness: An Approach to User-Centered Design (Boca Raton, London and New York: CRC Press 2012).

31 For an overview, see Paul Salmon et al., "What really is going on? Review of situation awareness models for individuals and teams". Theoretical Issues in Ergonomics Science 9 (2008), 297-323.

32 Ibid.

33 Harold Winters, Battling the Elements: Weather and Terrain in the Conduct of War (The Johns Hopkins University Press, 1998).

34 See e.g. Robert Jervis, “Cooperation under the security dilemma”. World Politics 30 (1978), 167-214. 
international system..$^{35}$ "Because one state's gain in power is another state's loss, great powers tend to have a zero-sum mentality when dealing with each other," writes John Mearsheimer. ${ }^{36}$

However, Tactical Advantage as such does not translate well into a traditional zerosum game or other theoretical decision-making games, since it merely states the relationship between the players in a tactical environment rather than the decision-making dilemmas facing those involved. The concept only establishes tactical advantagedisadvantage as a zero-sum dichotomy.

Elements that give one player a tactical advantage are sometimes referred to as a force multiplier, that is, factors that dramatically increase the effectiveness of the armed forces of one side over the other in a battle.

\section{Military operations and the operational environment}

\subsection{Introduction}

The environment strongly impacts military operations. ${ }^{37}$ Also referred to as the physical battlespace, the operational environment is comprised by numerous elements, both man-made and natural, and can be highly dynamic. ${ }^{38}$ The U.S. National Research Council has identified a series of natural parameters of particular importance to military operations, highlighting atmospheric, oceanographic, bathymetric and topographic, acoustic, geophysical and magnetic, and anthropogenic factors. ${ }^{39}$ "[T] he need for adequate and accurate environmental data on small scale is paramount for minimizing uncertainty and reducing risk," the Council states. ${ }^{40}$

In the Arctic, the operational environment is mostly natural (as opposed to man-made) - and extreme. It is vast, harsh, and isolated ${ }^{41}$ It is predominantly a maritime domain, which is also reflected in this study. Still, the Arctic differs significantly from other maritime areas, not least because it is covered by sea-ice much of the year and wrapped in a polar night during mid-winter. Operations in the Arctic "require special training, extreme cold-weather modifications for systems and equipment, and complex logistics support," the U.S. Navy notes in its 2014-2030

35 E.g. Graham Allison, Destined for War: Can America and China Escape Thucydides's Trap? (Boston \& New York: Houghton Mifflin Harcourt, 2018); Robert Gilpin, War and Change in World Politics (Cambridge University Press, 1981); John Mearsheimer, The Tragedy of Great Power Politics, updated ed. (W.W. Norton \& Co. 2014); A.F.K. Organski, World Politics (New York: Knopf, 1958); Kenneth N. Waltz, Theory of International Politics (Boston \& New York: McGrawl-Hill, 1979).

36 Mearsheimer, The Tragedy of Great Power Politics, 34.

37 Young, Arctic Politics.

38 Endsley, "Toward a Theory".

39 NRC, Environmental Information for Naval Warfare.

40 Ibid.

41 Kyle Christensen, The Arctic: The Physical Environment (Defence R\&D Canada 2010). DRDC-CORA TM 2010-193. 


\section{Torbjørn Pedersen}

Roadmap. ${ }^{42}$ Also, along with Antarctica, the Arctic is regarded the world's least observed region..$^{43}$ However, this tactically challenging environment not only poses risks to military operations. It also offers significant advantages to those who master these extremes.

\subsection{Below the surface}

Submarine operations require stealth. Although hull, quieting, and propulsion technology has been constantly refined over the last few decades, ${ }^{44}$ submarine operators must still make use of the natural environment to escape acoustic detection. ${ }^{45}$ "Prediction of the oceanographic environment is important for the proper use of [anti-submarine warfare] ASW sensors, as well as for other naval operations," noted the Central Intelligence Agency (CIA) in a 1984 report on the Soviet oceanographic research program. ${ }^{46}$

The Arctic seas present several notable advantages to those who seek to stay hidden. The region is "a beautiful place to hide", as one admiral put it, ${ }^{47}$ since a number of regional features reduce the risk of acoustic detection. The ice-cover, for one, prevents anti-submarine warfare surface vessels and aircraft from employing various systems, such as towed array sensors systems, dipping sonars and sonobuoys. ${ }^{48}$ Sea ice also renders optical and infrared sensors ineffective and reflects or scatters laser beams.

The constantly moving, and rumbling sea ice also creates ambient noise that masks the sounds of the submarine. ${ }^{49}$ Moreover, the uneven ice scatters acoustic waves, which complicates acoustic propagation predictions further..$^{50}$

The Arctic seas also have distinct temperature and salinity layers, which also scatter sounds. ${ }^{51}$ As they bend and reflect soundwaves, permanent or seasonal thermoclines and distinct shifts in water salinity can potentially provide acoustic cover for

42 U.S. Department of the Navy, U.S. Navy Arctic Roadmap 2014-2030, April 2014.

43 The World Meteorological Organization (WMO), "Year of Polar Prediction - From Research to Improved Environmental Safety". Press Release, 15 May 2017.

44 Anthony Wells, A Tale of Two Navies: Geopolitics, Technology, and Strategy in the United States Navy and the Royal Navy, 1960-2015 (Annapolis: Naval Institute Press, 2017); John Olav Birkeland, The potential of LIDAR as an antisubmarine warfare sensor. MPhil(R) thesis, University of Glascow, 2009.

45 Central Intelligence Agency (CIA), "The Soviet Oceanographic Research Program". A Technical Intelligence Report SW 84-10007 (1984, declassified on 5 March 2010).

46 CIA, "The Soviet Oceanographic Research Program", 11.

47 Chief of Naval Operations, Admiral James Watkins, quoted in Polmar \& Whitman, "Hunters and Killers", 157.

48 Wells, A Tale of Two Navies.

49 Sherry Sontag and Christopher Drew, Blind Man's Bluff: The Untold Story of American Submarine Espionage (New York: Harper 1999)

50 Wells, A Tale of Two Navies.

51 Harold Doebler, "Introduction to Sonar Scattering Layers". USL Technical Memorandum No. 932-77-64. (Fort Trumbull: U.S. Navy Underwater Sound Laboratory, 1964). 
submarines..$^{52}$ The salinity layers are seasonal and particularly distinct close to discharges of freshwater from rivers and, in the case of the Arctic, melting glaciers, where additional sound channels and shadows, or acoustic blind zones, may appear. ${ }^{53}$

Further, the Arctic seas are relatively shallow, which also complicates acoustic propagation, as the seabed also reflects and scatters soundwaves. ${ }^{54}$ Illustratively, the average depth of the Barents Sea, outside the Kola Peninsula, is 230 meters, ${ }^{55}$ while the average depth of the Atlantic Ocean as a whole is 3,646 meters. The Kara Sea averages a mere 131 meters.

Ocean tides and currents also provide tactical opportunities. Currents allow submarines to drift practically silently and cover considerable distances unnoticed over the duration of a dive, ${ }^{56}$ which could last for months. For instance, the Transpolar Drift could take a submerged submarine from the Kara and Laptev seas in the European Arctic to the Fram Strait, between Greenland and Svalbard. ${ }^{57}$ The Norwegian Atlantic Current, an extension of the Gulf Stream, serves as a conveyer between the Greenland-Iceland-United Kingdom (GIUK) gap and the Barents Sea. The West Spitsbergen Current, the northernmost extension of the Norwegian Atlantic Current, brings a flow of warm water from the Norwegian Sea into the Arctic Ocean, just off the western coast of Svalbard. However, currents may also create eddies, that can jeopardize undersea operations..$^{58}$

Equally important is bathymetric knowledge, that is, data about the seafloor "topography". Detailed underwater terrain models are essential to safe undersea navigation and mine counter-measures (MCM). As the Arctic is one of the least charted regions on Earth, a unique or superior access to high-resolution underwater terrain models would offer a distinct advantage. Bathymetry also strongly affects acoustic propagation..$^{59}$ Not only the depths, but also knowledge about the bottom sediments is essential in undersea warfare, for a number of reasons. The composition and stability of the seafloor affects sound propagation, ${ }^{60}$ but it is also a critical part of the operational environment. For instance, firm rock allows a submarine to rest on

52 "SEAPROF - Undersea Acoustic Performance Prediction System", SAES, undated. Accessed 25 October 2018 https://electronica-submarina.es/wp-content/uploads/2018/08/ SAES_SEAPROF_Acoustic_Model_english.pdf; Wells, $A$ Tale of Two Navies.

53 CIA, "The Soviet Oceanographic Research Program".

54 Wells, A Tale of Two Navies.

55 "Barents Sea", The Norwegian Polar Institute, accessed 30 May 2018. http://www.npolar. no/en/the-arctic/the-barents-sea/

56 Sontag and Drew, Blind Man's Bluff, 329.

57 Ibid.

58 "PLA Navy eyes China's deep-sea underwater glider after successful test shows it rivals US vessel”, South China Morning Post, 1 September 2016.

59 Jens Hovem, Marine Acoustics: The Physical Sound in Underwater Environments (Los Altos Hills: Peninsula Publishing, 2012).

60 Ibid., 59. 


\section{Torbjørn Pedersen}

the seafloor, blending in with the surrounding formations. ${ }^{61} \mathrm{Mud}$, on the other hand, could be used to bury mines. ${ }^{62}$

Even marine biology has operational relevance. Notably, organisms reflect and generate acoustics and affect the optical clarity of water. ${ }^{63}$

\subsection{Above the surface}

One of the most appreciated force multipliers in war history is weather. From the failed attempt of Mongol emperor Kublai Khan to invade Japan in 1281, the defeat of the Spanish Armada in 1588, the Battle of Waterloo in 1815, to the D-Day invasion in 1944, weather conditions have been credited for determining the outcome of battles and, thus, the course of history. ${ }^{64}$ "Despite the evolving technology in warfare, physical geography has a continuous, powerful, and profound effect on the nature and course of combat," conclude Harold A. Winters et al. in their detailed account, Battling the Elements: Weather and Terrain in the Conduct of War. ${ }^{65}$ "Weather affects soldiers, equipment, operations, and terrain. Cloud cover, wind, rain, snow, fog, dust, light conditions, and temperature extremes combine in various ways that affect human efficiency and limit the use of weapons and equipment", summarizes I. M. Datz. ${ }^{66}$

Ocean weather relates to the features of the ocean surface, where meteorology and oceanography meet. The structure of the sea surface includes local wind-generated waves as well as long ocean swells, both of which strongly impact the performance of surface ships. Waves are a potential hazard to navigation and a whole range of naval operations. ${ }^{67}$ Naval vessels, usually designed with semi-displacement V-shaped hulls optimized for speed and maneuverability, perform even worse in rough seas than civilian merchant vessels with their more U-shaped full-displacement hulls. Ocean weather and its inherent chaotic and turbulent motion add an additional protection layer for submarines by generating ambient noise and scattering acoustics.

Atmospheric weather refers to changes in the conditions of the atmosphere over a relatively short period of time. The National Weather Service (NWS), the lead weather forecasting outlet in the United States, issues over 25 different types of

61 "Sea Breeze 2017 Takes Anti-submarine Warfare Training to Advanced Level", U.S. Naval Forces Europe-Africa/U.S. $6^{\text {th }}$ Fleet, 23 July 2017. Accessed 8 November 2018 http://www. c6f.navy.mil/news/sea-breeze-2017-takes-anti-submarine-warfare-training-advanced-level.

62 Hovem, Marine Acoustics, 3.

63 CIA, “The Soviet Oceanographic Research Program”, 18.

64 Winters, Battling the Elements.

65 Ibid., 4.

66 I.M. Datz, Military Operations under Special Conditions of Terrain and Weather (New Dehli: Lancer 2004), 177.

67 Jim Thomson and Erick Rogers, "Swell and Sea in the Emerging Arctic Ocean". Geophysical Research Letters 41 (2014), 3136-3140. 
weather warnings, statements or watches, ${ }^{68}$ which relate to e.g. flash floods, thunderstorms, blizzards, snow and winter storms, fog, tornados, and hurricanes. Forecasts are essential to safe operations at sea, on land and in the air, as weather affects most aspects of military operations, from the advancing speed of ground forces and missile launches, to the safe operation of aircraft and the performance of space-borne sensors.

In the Arctic, the polar lows are a particularly dreaded hazard during winter. These intense mesoscale cyclones, also dubbed "Arctic hurricanes", are characterized by "severe weather in the form of strong winds, showers and occasionally heavy snow, which have sometimes resulted in the loss of life, especially at sea" ${ }^{69}$ The small size of polar lows and their rapid development make them difficult to represent in models. Therefore, they are notoriously hard to predict. ${ }^{70}$

Also, icing is a recurring hazard to air as well as naval operations in the Arctic region. On surface vessels, icing occurs when spray from the bow freezes on bulkheads, decks, and rigging. ${ }^{71}$ The ice can impede sensors and weapons, prevent deck operations, and reduce the ship's seaworthiness by adding weight and shifting its center of gravity. ${ }^{72}$

Climate is - as opposed to weather-measured over a longer period of time. Changes in climate, i.e., long-term weather patterns, are putting stress on existing weather forecasting models. Global warming triggers more extreme weather and climate events, such as heat waves and drought. "Changes in climate can potentially shape the environment in which we operate and the missions we are required to do," acknowledges a 2018 U.S. Department of Defense report on the impacts of climate change. ${ }^{73}$

Space weather is broadly defined as "the conditions on the Sun and in the solar wind, Earth's magnetosphere, ionosphere, and thermosphere that can influence the performance and reliability of space-borne and ground-based technological systems and endanger human life or health". ${ }^{74}$ It affects a range of systems crucial to military operations. "Known impacts include service outages, mission degradation and mission failure, data loss, sensor degradation, subsystem failure, launch delays, redesign

68 What's the Difference Between Weather and Climate?", NASA, undated. Accessed 20 November 2018. https://www.nasa.gov/mission_pages/noaa-n/climate/climate_weather. html

69 John Turner, Erik Rasmussen \& A.M. Carleton, "Introduction". In Erik Rasmussen \& John Turner, eds, Polar Lows: Mesoscale Weather in the Polar Regions (Cambridge University Press, 2003), 10 .

70 Ibid.

71 Lasse Makkonen, “Atmospheric Icing on Sea Structures”. CRREL Monograph 84-2 (1984).

72 Ibid.

73 U.S. Department of Defense, "Climate-Related Risk to DoD Infrastructure: Initial Vulnerability Assessment Survey (SLVAS) Report” (2018), 7.

74 Jonathan Eastwood, "The Science of Space Weather". Philosophical Transactions of the Royal Society A (2008), 4489. 


\section{Torbjørn Pedersen}

and retest, anomaly analyses, and the ultimate cost for each of the preceding," conclude H.C. Koons et al. ${ }^{75}$

The effects of space weather are particularly pronounced in the polar regions. ${ }^{76}$ The cusps allow charged particles to penetrate deep into the atmosphere, since they move more easily along inward-curving magnetic field lines. In contrast, closer to the Equator, the magnetic field is almost parallel to the Earth's surface and becomes an effective shield against space weather.

The bombardment of particles from space produces intense ionization in the lower ionosphere, which severely affects radio communications, for one. The impact on the ionosphere is known as the polar cap absorption effect. ${ }^{77}$ Certain frequencies may be completely blacked out, as high-frequency radio signals are absorbed rather than reflected by the ionosphere. ${ }^{78}$ This impact is "very closely associated with the occurrence of visual aurora and geomagnetic storms" ${ }^{79}$ Thus, communications in the High Arctic is a double challenge, since the highest latitudes already are beyond the reach of geostationary satellites, orbiting directly above the Earth's equator, and accordingly, outside the coverage of the most common satellite communications systems.

Moreover, changes in the ionosphere could also dramatically reduce the range of over-the-horizon (OTH) radar systems, which also make use of the reflecting ionosphere to increase their range. Space weather affects satellite signals and the reliability of the Global Positioning System (GPS), ${ }^{80}$ and can even damage the satellite itself. ${ }^{81}$

As military operations depend heavily on technology, space weather forecasting has become almost as important as traditional forecasting.

\subsection{Identifying targets}

Other fundamental elements of the operational environment are hostile targets, including enemy aircraft, missiles, surface vessels, and submarines. In order for operators and sensor systems to detect and identify a potential target, they must

75 H.C. Koons et al., "The Impact of the Space Environment on Space Systems". Aerospace Report No. TR-99 (1670)-1 (1999), 1.

76 D.C. Rose \& Syed Ziauddin, "The Polar Cap Absorption Effect". Space Science Review 1 (1962), 115-134.

77 Ibid.

78 Finn Lied, “Opening Speech". In Kristen Folkestad, ed, Ionospheric Radio Communication (Springer Science + Business Media, 1968); R.D. Hunsucker \& J.K. Hargreaves, The High-Latitude Ionosphere and its effects on Radio Propagation (Cambridge University Press, 2002).

79 Olav Holt, “Characteristics of Polar Cap Absorption”. In Kristen Folkestad, ed, Ionospheric Radio Communication (Springer Science + Business Media, 1968).

80 P.T. Jayachandran et al., "Canadian High Arctic Ionospheric Network (CHAIN)". Radio Science 44 (2009).

81 Baker et al. 1998. 
know some of its characteristics. A library of unique characteristics of any potential target - i.e., its measurements and signature -are essential to the performance of early-warning and weapons systems.

As a consequence of Russia's bastion defense, the European Arctic is a theater with multiple potential targets, whose measurements and signatures are of vital interest to various stakeholders. It is an operation area for Russia's largest strategic fleet - and consequently also multiple western surveillance and anti-submarine warfare capabilities. The Arctic is also a testing ground for new Russian weapons systems. In sum, the region displays a rich variety of new platforms and weapons systems.

Below the surface, acoustics is the most important means of target detection..$^{82}$ Passive sonar systems and operators seek to determine a target's signature based on e.g. a submerged submarine's propeller blade rate, shaft rate, number of propeller blades, cylinder firing rate, number of cylinders, power source, and/or turbine rate. ${ }^{83}$

However, hydrophones also pick up background noise, emitted from natural as well as man-made sources. In the Arctic, background noise would include an assortment of sources such as marine mammals, frequent storms and showers, rumbling ice and calving glaciers, trawlers, and creaking fishing gear. ${ }^{84}$ In order to detect a potential target, systems and operators must enhance the target signal and reduce the background noise..$^{85}$

Other detection systems include active sonars, but also different non-acoustic systems. A submarine can be detected visually, or by its wake, gas discharges, heat, bioluminescence, internal waves, neutrino emissions, or the Bernoulli hump, that is, the slight bulge in the surface created by a fast-moving submerged vessel. ${ }^{86}$ It could potentially also be detected by its overall electric, magnetic, seismic, and pressure influences. ${ }^{87}$

Magnetic detection methods were explored extensively toward the end of the Cold War. To detect a target by its magnetic influences, the systems required reference measurements from the region. "Geomagnetic measurements provide information on variations in the earth's magnetic field, the background against which magnetic methods for submarine detection must operate," the 1984 CIA report states. ${ }^{88}$ The

82 See Polmar \& Whitman, "Hunters and Killers", 161.

83 Arif Parvez \& Syed Muhammad Raza Jafri, "Noise Effect on Surface Ship Passive Sonar and Possible ASW Solution". Fournal of Information \& Communication Technology 7 (2013), 31-60.

84 See e.g. Sontag and Drew, Blind Man's Bluff; Hovem, Marine Acoustics.

85 Hovem, Marine Acoustics, 282.

86 Daniel Gerald Daly, "A Limited Analysis of some Nonacoustic Antisubmarine Warfare Systems”. Master thesis, Naval Postgraduate School, 1994.

87 "Underwater Multi-Influence Measurements as a Means to Characterize the Overall Vessel Signature and Protect the Marine Environment", SAES, 26 October 2017. Accessed 9 November 2018 electronica-submarina.com.

88 CIA, "The Soviet Oceanographic Research Program”, 14. 


\section{Torbjørn Pedersen}

"magnetic anomality" created by a submarine not only stems from the hull, ${ }^{89}$ but also from the "change in the electromagnetic conductivity of sea water (which lasts for several hours) in the wake of a submarine". ${ }^{90}$

The wake can be detected in other ways, too. Light Detection and Ranging (LiDAR), a laser technology, is used to detect lingering physical phenomena in the submarine's wake, which can be observed several kilometers behind the target. ${ }^{91}$ In the Arctic, even bioluminescent organisms, which are a dominant source of light during the polar night, ${ }^{92}$ may also reveal a wake, as the disturbance of a passing vessel will trigger bioluminescence. ${ }^{93}$

Above the surface, radar systems are particularly useful for target detection. Radars, which detect and locate objects by means of a return signal, can be mounted on most platforms and offer night-and-day imagery of potential targets. As with acoustics, the target's radar signature is obtained and added to the comprehensive libraries that are integrated in radar-based detection and weapons systems.

Other sensors include optical cameras and infrared devices, notably thermal imagery sensors, which can read the infrared heat signatures of objects based on the temperature differences caused by e.g. engines and plumes. Also used to detect and identify targets are electro-magnetic (EM) sensors and systems, which scan a wide range of radio frequencies for emissions from hostile sources. Radars, radio transmitters, and other sources that radiate - intentionally or unintentionally electro-magnetic energy, potentially reveal a distinctive emitter signature.

\section{Polar research and the operational environment}

\subsection{Current polar research}

Civilian research in the Arctic has changed drastically in recent years. In particular, the number of actors and nationalities participating in polar research activities has surged. The International Polar Year (IPY) 2007-2009, which was organized through the International Council for Science (ICSU) and the World Meteorological Organization (WMO) and covered both polar regions, involved more than 200 projects, with thousands of researchers from over 60 nations. ${ }^{94}$

The number of members of the International Arctic Science Committee (IASC) has almost tripled since it was established by the eight Arctic states in 1990. This

89 Daly, "A Limited Analysis".

90 Quoted in Polmar \&Withman, Hunters and Killers, 149.

91 Ibid.

92 Heather Cronin et al., "Bioluminescence as an ecological factor during high Arctic polar night”. Scientific Reports, 2016.

93 CIA, "The Soviet Oceanographic Research Program"; John Strand, Clarence Pautzke and Gordon Mitchell, "The Antisubmarine Warfare (ASW) Potential of Bioluminescence Imaging”. Office of Naval Research Technical Report 80-1 (1980).

94 “About IPY”, IPY, accessed 8 November 2018. http://www.ipy.org/index.php?/ipy/about/ 
non-governmental organization, which aims "to encourage, facilitate and promote cooperation in all aspects of Arctic research in all countries engaged in Arctic research and in all areas of Arctic research", ${ }^{95}$ has a total of 23 permanent members, including national research institutions from Austria, China, the Czech Republic, France, Germany, India, Italy, Japan, the Netherlands, Poland, Portugal, South Korea, Spain, Switzerland, and the United Kingdom. ${ }^{96}$

The increase in international polar research is also reflected in the turnout for the annual Arctic Science Summit Week (ASSW). In 2018, the summit drew a record crowd of 2,500 participants, who attended events such as the Arctic Business Meetings, the Arctic Science Symposium or the biennial Arctic Observing Summit (AOS) ${ }^{97}$ The summit has become steadily more popular since it was introduced in 2013. ${ }^{98}$

In Svalbard, a number of nations have established a research presence. The Research in Svalbard (RiS) database, which includes metadata from finished, in-progress and planned research projects in the archipelago, contains entries from more than 1,500 institutions from a total of 50 different nations. ${ }^{99} \mathrm{Ny}$-Ålesund, just 1,231 kilometers from the North Pole, now features permanent stations run by institutions from China, France, Germany, India, Italy, Japan, the Netherlands, Norway, South Korea and the United Kingdom. ${ }^{100}$ While terrestrial and marine biology has dominated research in Svalbard for decades, atmospheric and oceanographic research is becoming more popular. ${ }^{101}$ China, for instance, has atmosphere and oceanography as the number one and two disciplines in its Svalbard project portfolio. ${ }^{102}$

Polar research is increasingly collaborative. Even Arctic expeditions are becoming international. One current example is the Multidisciplinary drifting Observatory for the Study of the Arctic Climate (MOSAiC) expedition, led by Germany's Alfred Wegener Institute (AWI). The one-year expedition, which will take place in the central Arctic Ocean in 2019-2020, is presented as the largest Arctic research expedition ever and involves 60 research institutions from 16 different nations across Europe, Asia and North America. Its stated aims are to develop an understanding of

95 Susan Barr, "Preface". In Odd Rogne et al. (eds), IASC after 25 years. Special Issue of the IASC Bulletin (2015), 7.

96 “IASC History", IASC, accessed 8 November 2018. https://iasc.info/iasc/history

97 Personal communication (e-mail), 18 October 2018.

98 Ibid.

99 As of 18 October 2018.

100 "Research Stations in Ny-Ålesund”, Kings Bay, accessed 8 November 2018. https://kingsbay.no/research/research_stations/

101 Rogne et al., IASC after 25 years.

102 As of 18 October 2018. 


\section{Torbjørn Pedersen}

processes and feedbacks within and between the atmosphere, ocean and sea-ice, as the Arctic ice cover diminishes. ${ }^{103}$

International polar researchers are also brought together by thousands of smaller and larger events, from classroom-sized seminars and workshops to international programs and panels, such as the Arctic Monitoring and Assessment Program (AMAP), set up by the Arctic Council, and the International Panel on Climate Change (IPCC).

With more research comes better predictions. Researchers from the Nansen Legacy program, run by Norwegian research institutions, will spend more than 370 days at sea to "provide a 2020-2100 outlook for the expected state of climate, sea ice, and ecosystem, including near-term predictions". ${ }^{104}$ The Nansen Legacy promises to "increase high-resolution observational capabilities leading to an increase in future forecast reliability", in collaboration with international partners. ${ }^{105}$

In-situ observations are widely shared on various platforms, such as Copernicus, EMODnet and Pangaea. Further, research findings are made available through international publications. A journal profiling conducted by the Nordic Institute for Studies in Innovation, Research and Education (NIFU), shows the massive efforts by polar researchers to understand the natural elements of the remote polar regions and share their findings. ${ }^{106}$

\subsection{Ocean research}

Oceanography is one of the main research disciplines in the Arctic. Traditional regional oceanographic research nations, notably the Soviet Union and the United States, competed to gain an advantage in these harsh elements. Today, research efforts are far more international. According to the Norwegian Joint Headquarters (NJHQ), the number of research vessels in the region has steadily increased, to a total of 44 in 2017. During the 2017 season, some of the most ice-capable research vessels operating on the Atlantic side of the Arctic Ocean came from non-Arctic nations, including China (MV "Xue Long"), Germany (RV "Polarstern"), and the United Kingdom (RSS "James Clark Ross").

A notable newcomer to Arctic oceanographic research is China, which embarked on its first Arctic expedition with MV "Xue Long" in 1999 and opened a permanent research station in Svalbard in 2004. The "Xue Long" expeditions have resulted in comprehensive sailing manuals for the Northeast and the Northwest passages

103 "Developing a Process-Level Understanding", MOSAiC, accessed 9 November 2018. https://www.mosaic-expedition.org/about-mosaic/the-science.html

104 "Project Description", The Nansen Legacy, accessed 9 November 2018. https://arvenetternansen.com/?page_id=2483

105 Ibid.

106 Dag Aksnes, “Norwegian Polar Research \& Svalbard Research”. NIFU Report 2017:6. 
respectively. The manuals include "nautical charts and descriptions of ice conditions on the passage", according to the Chinese authorities. ${ }^{107}$

In August 2012, the Chinese also deployed a 15.5-ton buoy in the Norwegian Sea to provide real-time meteorological and oceanographic data from 70 degrees north. According to Chinese research institutions, it became "the first large-scale marine monitoring buoy China places in the Arctic region". ${ }^{108}$ The buoy was attached to a 3,800-meter cable with a total of 20 different instruments, including ConductivityTemperature-Density (CTD) sensors. ${ }^{109}$

China's oceanographic research in the Arctic is expected to expand significantly when MV "Xue Long 2" - a capable Polar Class 3 icebreaker - enters service in 2019.

Standard oceanographic measurements include CTD profiling, which establishes the shifting water temperatures, salinity layers and pressure through the water column. Another standard measurement is water velocity. In addition, polar researchers collect samples of sediments and establish the bathymetry of the seafloor with various echo sounders. All these parameters affect acoustics and are essential to the calibration of precise acoustic propagation models. ${ }^{110}$

In addition to surface research vessels and buoys, polar researchers use a whole variety of platforms to observe oceanographic conditions in the Arctic. Alfred Wegener Institute's deep-water observatory, Hausgarten, for instance, is a notable series of permanent stations in the Fram Strait, between Svalbard and Greenland. It provides "annual and continuously sensing and sampling in the water column and at the deep seafloor, visual observations, in situ experimental work", according to the German institute, ${ }^{111}$ and the data is made available online.

A seasonal example is Russia's drift-ice stations, from which Russian researchers have surveyed the central Arctic Basin for decades. ${ }^{112}$

Oceanographers also use commercial vessels to collect data. The FerryBox monitoring system, which incorporates a number of oceanographic sensors, is found on MS "Trollfjord", which traffics the coast of Norway, and MS "Norbjørn", on the cargo route between the Norwegian mainland and Svalbard. The FerryBox system is operated by members of the European Global Ocean Observing System (EuroGOOS) and returns a continuous stream of oceanographic data from the European Arctic to international researchers.

107 State Council Information Office of China, 2017.

108 "News", CHINARE5, accessed September 2012. http://www.chinare5.com/news/. Page currently unavailable.

109 Ibid.

110 Hovem, Marine Acoustics.

111 “LTER Observatory HAUSGARTEN", AWI, accessed 8 November 2018. https://www.awi.de/

112 Oleg Godin \& David Palmer, History of Russian Underwater Acoustics (Hackensack: World Scientific Publishing, 2008). 


\section{Torbjørn Pedersen}

The Arctic Regional Ocean Observing System (ArcticROOS), a regional branch of EuroGOOS, is only one of many relevant collaborations. It comprises a network of 20 institutions from nine European nations working to improve observations in, and oceanographic models for, the Arctic region through international collaboration. The network has announced that it will include more members, also from nations outside Europe, and transform into a Global Ocean Observing System "GOOS Regional Alliance for the Arctic". ${ }^{113}$

The European Union funds a number of programs, projects, and initiatives aimed at internationalizing Arctic research and making in-situ observations more available. Integrated Arctic Observation System (INTAROS), for instance, is an EU-funded project to develop a common platform for searches and access to data from databases across the Arctic region. ${ }^{114}$ Other EU-sponsored data-sharing initiatives include SeaDataNet and SeaDataCloud, which aim to facilitate international access to historical datasets owned by various national data centers. ${ }^{115}$

International collaboration and data-sharing also extend to bathymetry and the sediments of the Arctic seabed. The secrets of the Norwegian continental shelf, which covers a large share of the European Arctic, have also been uncovered by the multi-year Mareano program. Through a number of surveys, research institutions have provided and shared details about e.g. bathymetry, sediments, and biology on the Arctic seabed. ${ }^{116}$

Although high-resolution details about the seabed in coastal waters usually remain classified, they are becoming more readily available through end-user sharing. The Olex echo sounder, for instance, allows users to upload their own 3D seabed data and thus contribute to an increasingly comprehensive sea floor map available to all users. ${ }^{117}$

\subsection{Atmospheric research}

Climate change is widely regarded as one of the major challenges facing mankind, and most governments and national research councils have accordingly made atmospheric research a priority. As the Arctic region is warming up almost twice as fast as the planet's average, ${ }^{118}$ it has become a key region for monitoring changes in the

113 “Arctic ROOS”, EuroGOOS, accessed 9 November 2018. http://eurogoos.eu/roos/arctic-roos/

114 "INTAROS: Integrated Arctic Observation System", NERSC, accessed 16 November 2018. https://www.nersc.no/project/intaros

115 “About us", SeaDataNet, accessed 9 November 2018 https://www.seadatanet.org/About-us/ SeaDataCloud

116 Mareano homepage, accessed 9 November 2018. http://www.mareano.no

117 "Collected Sea Floor Data", Olex, accessed 8 November 2018. http://www.olex.no/dybdekart_e.html

118 "Climate Change in the Arctic: Status and Development", The Norwegian Polar Institute, 4 March 2014, accessed 13 November 2018. http://www.npolar.no/en/themes/climate/thearcticl 
atmosphere. "We strongly note the need for increased effort and urgent attention supporting further international scientific collaboration focusing on the warming trend in the Arctic," reads a joint statement from the Second Arctic Science Ministerial in October 2018. ${ }^{119}$

International collaboration not only relates to climate issues but extends to weather forecasting. The Polar Prediction Project (PPP), initiated by the World Meteorological Organization (WMO), ${ }^{120}$ is a 10-year project (2013-2022) set to improve weather and environmental prediction services for the polar regions through extensive international collaboration. The flagship activity of the Polar Prediction Project, the Year of Polar Prediction (YOPP), aims to enable "a significant improvement in environmental prediction capabilities for the polar regions and beyond, by coordinating a period of intensive observing, modelling, verification, user-engagement and education activities". ${ }^{121}$ Relevant datasets are provided by a number of participating research institutions from all over the world. The models are set to improve predictions on different time scales, from hours to seasonal. The steering group includes members from 14 different nations, including China, Russia, and the United States. ${ }^{122}$

Arctic weather forecasting has always been a major challenge, much due to few in-situ observations and the shortcomings of common models, not designed with Arctic conditions in mind. Now, however, models are improving and observations have become more numerous and internationally shared. ${ }^{123}$

In Svalbard, extensive international research collaborations have been established to advance international atmospheric research. In Ny-Ålesund, which is isolated from all sources of pollution, the research community has defined atmospheric research as one of four research flagship programs. The program aims to establish "a unique international long-term atmospheric monitoring and observation platform" and create "a supersite, allowing investigations of the complex Arctic System with a multidisciplinary approach". ${ }^{124}$ Flagship participants include research institutions from China, Germany, India, Italy, Japan, Norway, Poland, Russia, South Korea and Sweden.

Another collaboration in Svalbard, the Svalbard Integrated Arctic Earth Observing System (SIOS), was set up to allow researchers from different nations "to access

119 Joint Statement of Ministers on the Occasion of the Second Arctic Science Ministerial. Berlin, 28 October 2018.

120 WMO, Resolution 17 at the Executive Council Meeting (EC-64), 25 June - 3 July 2012.

121 Polar Prediction, homepage, accessed 9 November 2018. https://www.polarprediction.net

122 "Steering Group Members", Polar Prediction, accessed 9 November 2018. https://www. polarprediction.net/steering-group/

123 Personal communication (e-mail), 5 November 2018.

124 Norwegian Polar Institute, "Atmospheric research in Svalbard - a flagship program" Brief Report Series 022 (2011), 3. 


\section{Torbjørn Pedersen}

instruments, acquire data and address questions that would not have been practical or cost effective for a single institution or nation alone" ${ }^{125}$ According to the consortium of institutions from 10 nations that operate research facilities in Svalbard, ${ }^{126}$ "SIOS focuses on processes and their interactions between the different spheres, i.e., biosphere, geosphere, atmosphere, cryosphere and hydrosphere". ${ }^{127}$

Observations made in the Arctic not only feed data to various models but also serve as reference points for satellite-based observations. Remote sensing can be affected by e.g. sensor degeneration and calibration uncertainties and require validation from in-situ observations. ${ }^{128}$ Accordingly, and paradoxically, the need for in-situ observations increases with more remote sensing. The number of satellites in orbit is currently 4,871, according to the U.N. Index of Objects Launched into Space, ${ }^{129}$ up almost five percent from the previous year. ${ }^{130}$

The Arctic in general, and Svalbard in particular, is also well suited for research on space weather. Sitting under the magnetic cusp, the Svalbard archipelago has become a hub for ionospheric and magnetospheric research. The EISCAT Svalbard radar facility, located just outside Longyearbyen, featuring one 32-meter steerable and one 42-meter fixed antenna, provides valuable measurements of the ionosphere and the atmosphere for EISCAT partners.

Space weather is also observed with optical sensors. The Kjell Henriksen Observatory (KHO), next to the EISCAT radars, is the only permanent observatory that allows international researchers to observe daytime aurora, that is, during the polar night. ${ }^{131}$ Other auroral observation sites in the European Arctic for night-time observations include Apatity (Russia), Kiruna (Sweden), and Tromsø (Norway). ${ }^{132}$ The latest addition to optical auroral observatories in northern Europe is the ChinaIceland Joint Arctic Science Observatory (CIAO) at Karholl (Iceland). ${ }^{133}$

125 "The Observing System", SIOS, accessed 9 November 2018. https://sios-svalbard.org/ObservingSystem

126 “The SIOS Consortium”, SIOS, accessed 9 November 2018. https://sios-svalbard.org/Consortium

127 "The Observing System", SIOS.

128 See e.g. Paul Simon, "Lecture 2: Instrument intercomparison". ESA - National Remote Sensing Center of China (NRSCC) Dragon Program, 19 October 2006.

129 "Online Index of Objects Launched Into Space", U.N. Office of Outer Space Affairs, accessed 13 November 2018. http://www.unoosa.org/oosa/osoindex/search-ng.jspx?lf_id=

130 Ibid.

131 Network for Groundbased Optical Auroral Research in the Arctic Region, In the Light of the Aurora: Optical Auroral Research in Northernmost Europe (Copenhagen: Nordic Council of Ministers, 2009).

132 Ibid.

133 "The Construction at Karholl”, China-Iceland Joint Arctic Observatory (CIAO), accessed 8 November 2018. https://karholl.is/en/ 


\subsection{Polar research and target detection}

Target detection relies on various sensors. According to the U.S. Intelligence Community, sensors used in Measurement and Signatures Intelligence (MASINT) "include, but are not limited to, radar, optical, infrared, acoustic, nuclear, radiation detection, spectroradiometric, and seismic systems as well as gas, liquid, and solid material sampling systems". ${ }^{134}$ These sensors also have non-military research applications and are also found on civilian platforms. Civilian and military hardware, firmware, and software - as well as their performance - may well be vastly different. However, increasingly, armed forces use commercial-off-the-shelf (COTS) equipment ${ }^{135}$ which inevitably narrows the gap in the performance of military and civilian systems.

Below the surface, sonars are used extensively in polar research. Passive sonars are employed in Arctic studies of underwater biological activity, particularly involving marine mammals, but also to monitor non-biological dynamics, such as calving glaciers and melting ice. They are also integrated in the towed streamers used in seismic profiling, to survey sub-bottom layers. The seismic survey set-up is supposedly similar to arrays used in anti-submarine warfare. "In principle, the same techniques can be used to locate submarines, except that the submarine becomes the source of energy received by the hydrophone array," the CIA report concludes. ${ }^{136}$

Hydrophones are also employed in studies of man-made noise. A number of projects have aimed to explain how the sounds of ships, seismic air guns, and pile-driving harm, disturb, and confuse marine life. ${ }^{137} \mathrm{~A}$ prerequisite for such studies is to identify the various frequencies emitted from these sources. A single vessel, for instance, creates sounds from moving parts of the main and service engines, propellers, cavitation, vibrations in the hull, etc. ${ }^{138}$ In sum, researchers contribute to a comprehensive understanding of ocean acoustics, which is also relevant for target detection.

Polar researchers use a number of other sensors that could potentially also be used in anti-submarine warfare, such as state-of-the-art multi-beam sonar arrays, magnetometers, microstructure profilers, which detect internal waves and turbulence on a micro-scale, and airborne LiDAR systems. The latter is employed in bathymetric surveys. In Svalbard it is used to map changes in glaciers and ice caps. ${ }^{139}$

134 U.S. Permanent Select Committee on Intelligence, "IC21: The Intelligence Community in the $21^{\text {st }}$ Century”. Staff Study (1996). Accessed 1 June 2018. https://www.gpo.gov/fdsys/ $\mathrm{pkg} / \mathrm{GPO}-\mathrm{IC} 21 / \mathrm{html} / \mathrm{GPO}-\mathrm{IC} 21-7 . \mathrm{html}$

135 Daly, "A Limited Analysis".

136 CIA, "The Soviet Oceanographic Research Program", 13.

137 Øystein Solheim Pettersen, "A Study of Radiated Noise from Fishing Vessels". MSc Thesis, NTNU, 2017.

138 Ibid.

139 Jonathan Bamber et al., "Elevation changes measured on Svalbard glaciers and ice caps from airborne laser data". Annals of Glaciology 42 (2005). 


\section{Torbjørn Pedersen}

New and promising oceanographic research platforms also have anti-submarine warfare application. Notably, autonomous underwater vehicles (AUVs) are increasingly used in polar research. ${ }^{140}$ These vehicles have several advantages over traditional research platforms, as they can access shallow waters and operate under sea-ice. ${ }^{141}$ Underwater gliders, one type of AUVs using buoyancy-based propulsion, have proven particularly effective as a research platform in the Arctic Ocean. ${ }^{142}$ Their extreme endurance make them highly attractive both as research and anti-submarine warfare platforms. Inexpensive and expandable, they are well suited for mine countermeasures (MCM) purposes.

Above surface, radars have countless civilian applications. Outside Longyearbyen, the two European Incoherent Scatter (EISCAT) radars have allowed operating partner institutions from China, Finland, Germany, Japan, Norway, Sweden, and the United Kingdom, as well as others, to observe disturbances in the ionosphere and magnetosphere. However, the dual-purpose potential of research radars has been subtly acknowledged by the Norwegian authorities. When China offered to add a third radar - a 50-meter antenna - to the EISCAT facility in Svalbard, the government declined, citing that "the technology also has other uses". ${ }^{143}$ In addition to supplementing the existing research areas, the purpose of the new Chinese antenna was to map and track space debris as well as "measuring astronomical objects" at a high resolution with a Very Long Base Interferometer (VLBI). ${ }^{144}$ Mainland EISCAT radar facilities have already been tested for space debris tracking. The Tromsø (Norway) site has proved able to detect objects down to two centimeters in size, at an altitude of $500-1,500$ kilometers. ${ }^{145}$

Polar research is also advancing and refining unmanned aerial technology. The Arctic has recently become a notable laboratory for unmanned aerial vehicles (UAVs). In Ny-Ålesund, international researchers collaborate to overcome challenges related to the extreme environment of the Arctic, such as poor battery performance, icing on wings, propellers and sensors, and command-and-control issues in a region that lacks mobile phone infrastructure and broadband geostationary

140 Maxime Geoffroy et al., "AUV-based acoustic observations of the distribution and patchiness of pelagic scattering layers during midnight sun”. ICES fournal of Marine Science 74 (9) (2016).

141 Summarized in ibid.

142 See e.g. Acoustic Technology for Observing the interior of the Arctic Ocean (ACOBAR), an EU FP7 project (2008-2012) coordinated by Nansen Environmental and Remote Sensing Center (NERSC). https://acobar.nersc.no

143 Lars Egil Mogård, "Nord nei til Kina-radar på Svalbard”, NRK, 11 September 2014.

144 Multiconsult, "Delplan for EISCAT Svalbard Radar: Beskrivelse og bestemmelser". 17 December 2012.

145 Heiner Klinkrad et al., "Europe's Eyes on the Sky: A Proposal for a European Space Surveillance System”. ESA Bulletin 133 (2008), 42-48. 
satellite communication coverage. ${ }^{146}$ Technological advances here would inevitably be transferable to target detection platforms and make them more capable of Arctic operations.

\section{Arctic secrets uncloaked}

\subsection{Proliferation of knowledge}

Polar researchers are incrementally understanding more of the remote Arctic environment. A number of nations, both Arctic and non-Arctic, are currently conducting polar research in this sensitive operational area. Expeditions and programs usually involve multi-national teams, and in-situ observations made available online. Massive research efforts in recent years alone have produced thousands of articles on Arctic matters in peer-reviewed publications. ${ }^{147}$

Polar research nations have committed to sharing even more of their research data. The Scientific Cooperation Agreement, which entered into force in 2018, is adopted by the eight members states of the Arctic Council. According to Article 7 of the agreement,

The Parties "shall support full and open access to scientific metadata and shall encourage open access to scientific data and data products and published results with minimum time delay, preferably online and free of charge or at no more than the cost of reproduction and delivery. ${ }^{148}$

The Arctic states are also committed to "facilitate the distribution and sharing of scientific data and metadata". ${ }^{149}$

In the same spirit, national and European research funders increasingly insist on open-access publication of research that has received national funding. In September 2018, the research councils of Austria, France, Ireland, Italy, Luxemburg, the Netherlands, Norway, Poland, Slovenia, Sweden and the United Kingdom, as well as the European Commission, announced a joint initiative to "make full and immediate Open Access to research publications a reality". ${ }^{150}$

The sum amounts to a vast proliferation of data from, and knowledge about, the Arctic operational environment. Relentlessly, elements of the operational environment have become more familiar to a wider audience. Meteorological and oceanographic data, ice charts, atmospheric and ionospheric studies, acoustic propagation

146 Torbjørn Pedersen, "Collaboration on Drone Issues”. Svalbard Science Forum Newsletter, 8 April 2016.

147 Aksnes, "Norwegian Polar Research".

148 Agreement on Enhancing International Arctic Scientific Cooperaton (adopted 11 May 2017, entered into force 23 May 2018), Article 7.

149 Ibid.

150 “cOAlition S", Science Europe, 4 September 2018. Accessed 9 November 2018. https:// www.scienceeurope.org/coalition-s/ 


\section{Torbjørn Pedersen}

predictions, and even Arctic-adapted UAV and glider technology, are already readily accessible across national borders.

During the Cold War, the Soviet Union and the United States competed to get the better understanding of the operational environment. The 1984 CIA report concluded that the Soviets tried to "offset pronounced U.S. advantages in acoustic submarine detection" by gaining a better understanding of oceanographic conditions. ${ }^{151}$ The agency assessed that "the strongest civilian efforts seem to be in theoretical ocean dynamics to support both ASW and weather research. In general, the quality of many Soviet efforts is improving at a rate that could make them the world leaders in most fields of oceanography". ${ }^{152}$

The current proliferation of environmental data and knowledge will inevitably assist more stakeholders in achieving a similar Situation Awareness of the region. The trend may ultimately diminish the Tactical Advantages of traditional stakeholders, who, until now, could turn superior knowledge of the Arctic operational environment into a force multiplier.

\subsection{Environmental data and situation awareness}

Situation Awareness in the Arctic operational environment involves a clear perception of all the relevant elements of the area. As the Arctic Ocean is a harsh and largely ice-covered maritime area, and surrounded by scarcely populated or uninhabited islands and territories with little or no infrastructure, this study has stressed the importance of understanding the natural elements of this predominantly maritime Arctic environment, both below and above the ocean surface. In addition, vital to any military operation is also the ability to detect targets.

Polar research is indeed highly relevant for military operations in the Arctic. As demonstrated above, an understanding of the natural elements is paramount to all operations - undersea, surface, or aerial - and can determine the outcome of a given battle.

The accelerating flow of environmental data from the Arctic seas does not translate directly into a high-level or internationally shared Situation Awareness. In the modern Information Age, assimilating in-situ observations and data into actually needed information may potentially be as large a challenge as collecting them. ${ }^{153}$ Developing Situation Awareness is in some ways indistinguishable from intelligence tradecraft, which involves the processing of data and information into assessments and predictions (intelligence) that their audience can act on. Situation Awareness "involves far more than merely being aware of numerous pieces of data. It also requires a much

151 CIA, "The Soviet Oceanographic Research Program”, iii.

152 Ibid, iv.

153 Endsley \& Jones, Designing for Situation Awareness. 
more advanced level of situation understanding and a projection of future system states", Mica Endsley finds. ${ }^{154}$

The challenges of assimilating clutters of environmental data into higher levels of Situation Awareness can be illustrated by the complexities of the U.S. Navy Environmental Prediction System. This state-of-the-art system combines 4-Dimensional Variational Data Assimilation (4D-VAR), at least two different ocean circulation models, four waves, surf and tides models, two ice models, and three atmospheric models. ${ }^{155}$ The system provides real-time, high-resolution and three-dimensional models of the operational environment. Predictions and forecasts are continuously updated, as these data assimilation schemes allow the continuous inflow of data from various sensors, both in-situ and remote. ${ }^{156}$

Notwithstanding, commercial off-the-shelf (COTS) models and systems are rapidly becoming more sophisticated and offer increasingly better predictions. Improvements in commercial models and systems are likely to continue, as demand from civilian users grows and computer processing power increases. Widely available and improved systems, as well as broader international collaboration and data-sharing, will inevitably affect Situation Awareness and enable more stakeholders to make better predictions of the state of Arctic elements.

\subsection{Leveling the Arctic battlefield}

While civilian research is increasingly collaborative, military confrontations are crudely competitive. As noted, one actor's tactical advantage translates into an adversary's disadvantage. " $[\mathrm{T}]$ hat navy possessing a superior knowledge of the environment and knowing how to take tactical advantage will be the victor," Admiral of the Soviet Fleet, Sergey Gorshkov, once stated. ${ }^{157}$ The same appreciation is also found in modern military doctrines. "The commander who can best measure and take advantage of the weather and terrain conditions has a decided advantage over his opponent," asserts a U.S. Army Field Manual. ${ }^{158}$

Russia assumes that it holds a distinct advantage over others in the Arctic due to a range of factors, including extensive civilian, military and dual-use infrastructure as well as military training activity in the region, but also because of its long tradition of polar research. As acknowledged by Andrei Kokoshin, who held high-ranking positions within the Russian Ministry of Defense and on the Defense Council during the 1990s: ${ }^{159}$

154 Endsley, "Toward a Theory".

155 Burnett et al., "Overview of Operational Ocean Forecasting".

156 Ibid.

157 Quoted in CIA, “The Soviet Oceanographic Research Program”, 1.

158 U.S. Army Field Manual 100-5 (1993).

159 Åtland, “The Introduction, Adoption and Implementation”. 


\section{Torbjørn Pedersen}

The North suits us best of all; the efforts and sacrifices of Russian and Soviet polar explorers have provided us with an enormous, unique knowledge relating to the Arctic regions - [knowledge about] ice conditions, hydrology and hydrography, climate and weather conditions, etc. This gives Russia important advantages in this zone, particularly for submarines ${ }^{160}$

Others suggest that the United States holds the upper hand in the High Arctic. Anthony Wells, who has worked for both U.S. and British intelligence as well as their navies, asserts that the United States has "a huge tactical advantage over any threat under the Arctic ice", ${ }^{161}$ partly due to its vast research on acoustic propagation under the icecap.

Most aspects related to undersea warfare are classified in nature, ${ }^{162}$ and this study certainly does not have the prerequisite to conclude on which nation holds an advantage over others in an Arctic zero-sum game. However, it does postulate that the international proliferation of knowledge about the Arctic operational environment diminishes the tactical advantages that decades of Russian and U.S. polar research may have provided. As the secrets of the Arctic are uncloaked, and as differences in Situation Awareness (SA) across nations become less pronounced, the battlefield is correspondingly more levelled.

The implications are paradoxical. Most challenges facing mankind, spanning from human health issues to broader ramifications of global warming, call for broad international research collaboration. Through multi-national projects, international workshops, data-sharing and publications, the quality of research is improving. Sharing also allows for replication, validation, and extension of empirical results. ${ }^{163} \mathrm{~A}$ better understanding of the Arctic environment is essential, not only in order to govern regional ecosystems or safeguard human life and property at sea, but also to predict the effects of climate change on a global scale. International research collaboration is, in this context, to everyone's benefit. As noted in a joint statement at the Second Arctic Science Ministerial:

Costs can be reduced, and outcomes improved, by further promoting the sharing of research infrastructure and observing systems, and by making scientific data and publications - whenever possible - freely and openly available ${ }^{164}$

Still, this study stresses that polar research also has a zero-sum dimension. As demonstrated, the stakeholder with the best knowledge of a given operational environment

160 Kokoshin, translated in Åtland, "The Introduction, Adoption and Implementation”, 509.

161 Wells, A Tale of Two Navies, 62.

162 Kathleen Hicks et al., "Undersea Warfare in Northern Europe". A Report of the CSIS International Security Program (2016), viii.

163 Andreoli-Versbach and Mueller-Langer, "Open access to data: An idea professed but not practiced”. Research Policy 43 (2014), 1621-1633.

164 Joint Statement of Ministers on the Occasion of the Second Arctic Science Ministerial. Berlin, 28 October 2018. 
may also provide a Tactical Advantage for its military units in a battle. Indeed, superior Situation Awareness represents a force multiplier.

The implication is that the stakeholders who master the Arctic extremes could benefit from slowing the proliferation of knowledge and keeping the region exclusive, contrary to prevailing trends. In order to maintain a potentially decisive advantage if push comes to shove, protecting the secrets of the Arctic operational environment might be in a nation's best interest.

\section{Acknowledgements}

The author would like to thank the Norwegian Ministry of Defense for financial support (Grant No. 7000164-100) as well as experts in various fields of research notably Mårten Blixt, Alf Håkon Hoel, Frank Nilsen, and the anonymous reviewers - for comments on earlier drafts of this study. Thanks are also extended to staff members of the Norwegian Joint Headquarters, the Norwegian Defense Research Establishment, and the Norwegian Meteorological Institute for providing much appreciated empirical data. 